\section{Is the anterolateral ligament the smoking gun to explain rotational knee laxity or just vaporware?}

\author{
João Espregueira-Mendes (1) 1,2,3,4,5
}

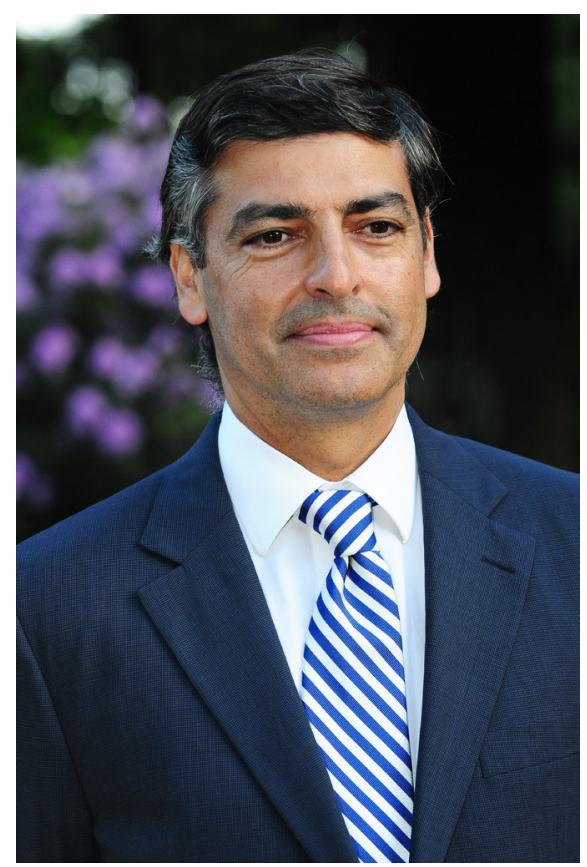

Since the publication of the 'discovery' of a new knee ligament in 2013, coined as anterolateral ligament (ALL), ${ }^{1}$ the scientific research into this 'new' anatomical structure has grown exponentially in the past years. The Journal of ISAKOS (JISAKOS) publishes in this issue three studies on the anatomy of the anterolateral capsule (ALC) of the $\mathrm{knee}^{2}$ and the biomechanics of the combined reconstruction of the anterior cruciate ligament (ACL) and the ALL. ${ }^{34}$

The history of the ALL takes us more than one century back to Segond's

\footnotetext{
${ }^{1}$ Clínica do Dragão, Espregueira-Mendes Sports Centre FIFA Medical Centre of Excellence, Porto, Portugal ${ }^{2}$ Dom Henrique Research Centre, Porto, Portugal ${ }^{3}$ School of Medicine, University of Minho, Braga, Portugal

${ }^{4}$ ICVS/3B's-PT Government Associate Laboratory, Braga/ Guimarães, Portugal

${ }^{5} 3 B^{\prime}$ 's Research Group-Biomaterials, Biodegradablesand Biomimetics, Headquarters of the European Institute of Excellence on Tissue Engineering and Regenerative Medicine, University of Minho, AvePark, Parque de Ciência e Tecnologia, Zona Industrial da Gandra, Barco, Guimarães, Portugal
}

Correspondence to João Espregueira-Mendes, Espregueira-Mendes Sports Centre, Clínica do Dragão, Porto 4350, Portugal;

espregueira@dhresearchcentre.com works, ${ }^{5-7}$ as well as to some other reports (earlier than 2013) of this structure. ${ }^{8-10}$ Despite much controversy and conflicting findings on the macroscopic anatomical, histological and MRI of the ALL, ${ }^{11-22}$ a consensus paper by international knee experts has characterised the ALL as a structure within layer 3 of the ALC. ${ }^{23}$ Nonetheless, if the ALL is really a distinct ligament structure or a thickening of the ALC remains open for debate. To better understand the phenotype of the ALC, Iseki et $a l^{2}$ evaluated the histology, immunohistochemistry and genetic expression of the ALC from paediatric specimens to investigate if there are any ligament-like characteristics. They found no discernible histological and immunohistochemical characteristics consistent with a ligament phenotype and that the ligament genetic markers (scleraxis and tenomodulin) were largely absent and poorly expressed in the ALC. Their methodology still needs to be replicated in adult specimens, but their findings suggest that the ALC does not display ligament-like characteristics and do not support the belief that there is a distinct ligament at the ALC.

In a recent systematic review of MRI studies, ${ }^{20}$ high variability was found in the identification of the ALL, which appeared in 51\%-100\% of all assessed knees (with a very high intraobserver and interobserver reliability rates), and the entire portion of the ligament was often not seen. These findings suggest that the ALL may not really exist as a distinct ligament, which goes in line with several other publications. ${ }^{15-19}$ Being the case that the ALL was not a defined ligament, performing an anterolateral ligament reconstruction (ALLR) does not recreate the native anatomy of the knee, but should rather be considered as a lateral non-anatomical augmentation procedure. $^{2}$

Lateral extra-articular tenodesis (LEAT) is being performed since the 1980s but has recently gained renewed interest. LEAT or ALLR - are performed in the ACL-deficient knee in patients with highrisk profile of reinjury and aim to better control the knee internal rotation and Lateral augmentation procedures-either decrease the risk of graft tear. The ALL strength varies between $49.9 \mathrm{~N}^{24}$ and $204.8 \mathrm{~N},{ }^{25}$ which is lower compared with the strength of the iliotibial band (487.9 $\mathrm{N}){ }^{26}$ ALC $(319.7 \mathrm{~N})^{26}$ or the distal iliotibial tract $(769 \mathrm{~N}) .{ }^{27}$ The strength of the iliotibial band (as compared with the ALL) suggests that this structure would be more fitted to withstand the high rotational torques. Indeed, adding a LEAT significantly decreases the forces at the ACL graft, ${ }^{28}{ }^{29}$ but an ALLR produces only a modest decrease. ${ }^{30}$ The role of ALLR is still not well established and is currently not being broadly used in daily clinical practice, and thus, the biomechanical studies are still an important step to investigate the effect of adding an ALLR on the knee stability and contact pressures.

Two of the studies published in this JISAKOS issue explore the biomechanics of anterolateral augmentation procedures in the setting of an ACL-deficient knee. ${ }^{34}$ Neri et $a l^{3}$ performed a cadaveric biomechanical study comparing ACL reconstruction isolated and combined with five different anterolateral augmentation procedures-ALLR and modified versions of Ellison, deep Lemaire, superficial Lemaire and MacIntosh LEAT procedures. They found that in the setting of an anterolateral-deficient knee, only the ALLR and Ellison procedures restored internal rotation laxity to the native intact state over the full range of knee flexion. The deep and superficial Lemaire and MacIntosh, although better controlling internal rotation, overconstrained the knee. The same group ${ }^{4}$ performed a pilot biomechanical study on the tibiofemoral lateral compartment contact pressures after ACL reconstruction combined with the same five anterolateral procedures described in Neri and colleagues. ${ }^{3}$ They found that the ACL reconstruction combined with ALLR or with the Ellison procedure did not change the contact pressures, while the Lemaire (either deep or superficial) and MacIntosh procedures increased the contact pressure during tibial internal rotation. However, this study only includes four specimens which highly increases the risk of type II error,and this should be taken into account when interpreting their findings. In opposition to their findings, conflicting evidence ${ }^{31}$ has shown no significant increase in the tibiofemoral compartment after ACL reconstruction with LEAT and, despite that the findings from Neri et $a l^{4}$ that suggest an increased risk of knee overconstrain and subsequent risk of cartilage wear after ACL reconstruction with 
Lemaire and MacIntosh procedures, long-term clinical studies have shown no increase in the rate of knee osteoarthritis when a LEAT is added to the ACL reconstruction. ${ }^{32}$ Other biomechanical studies have reported opposite results when comparing traditional LEAT techniques and ALLR. ${ }^{33}{ }^{34}$ Inderhaug et $a l^{33}$ showed that while deep Lemaire and MacIntosh procedures restored native rotational kinematics, the ALLR failed to restore normal internal rotation and underconstrained the knee. Trentacosta et $a l^{34}$ also showed that the LEAT technique using the iliotibial band better restored the intact kinematics as compared with ALLR. Other studies ${ }^{35-37}$ have found comparable biomechanical outcomes between the two techniques and with no advantage of one over the other. Among other confounders, the results may vary between studies due to techniques employed and fixation angle and fixation site, as it has been shown that these can highly influence residual laxity after ALLR. ${ }^{38}$ Results from the pool of biomechanical studies discussed earlier suggest that anterolateral procedures using the LEAT seem to be superior in controlling rotational laxity due to ACL insufficiency, ${ }^{33}$ but no definitive conclusion still cannot be achieved due to some conflicting findings. ${ }^{35-37}$

The addition of lateral augmentation procedures-either LEAT or ALLR-to ACL reconstruction remains one of the most controversial topics in ACL research, but their role in controlling high rotational laxity and protecting the graft in patients with high-risk profile has gained increasing support. Indeed, the Stability study ${ }^{40}$ has shown that adding a LEAT to an anatomical ACL reconstruction reduces the risk of clinical failure by $38 \%$ and graft rupture by $67 \%$ as compared with ACL reconstruction alone. In line with the renewed interest in LEAT, clinical studies ${ }^{41-44}$ have reported the results of combined ACL and ALLR, suggesting superior outcomes when compared with ACL reconstruction alone. In patients displaying high-grade pivot-shift, the addition of LEAT $^{4546}$ or ALLR ${ }^{47}$ seem to result in significant improvement in controlling rotational laxity. However, in patients where concomitant high-grade ALL injury is present, Ahn et al $l^{49}$ have showed that there may be an increased risk of residual rotational laxity, even when an ALLR is performed; however, these results should be viewed with caution as there are some limitations associated with unbalanced groups in the sample size and the poor capability of MRI to discriminate the grade of ALL injuries. ${ }^{2050}$ In a similar fashion, when the LEAT or ALLR augmentation procedures are performed during ACL reconstruction revision cases, the addition of these augmentation procedures shows similar clinical and functional outcomes when comparing to isolated ACL revision, but displays a better control of rotational laxity. ${ }^{47}$ 51-53 Although both procedures seem to play a meaningful clinical role as an augmentation in primary and revision ACL reconstructions, the role of the ALL in restoring the knee native kinematics is still controversial, with some studies demonstrating no significant contribution of the ALL in controlling tibial internal rotation. ${ }^{54-56}$ More importantly, we still do not know which technique will yield better clinical outcomes and a greater reduction of the risk of graft tear. Future research should focus on highpowered and high-quality randomised controlled trials comparing ACL reconstruction combined with either LEAT or ALLR with systematic approaches (surgical indications, graft selection, surgical technique, graft positioning and fixation) to investigate if there is any superiority of any of these techniques in clinical improvement, laxity restoration and risk of graft tear. Future clinical trials comparing both techniques and with long-term follow-up should shed light on the effect of the potential risk of overconstraining the knee in the incidence of knee osteoarthritis.

Only time will tell if the ALL will be the smoking gun to explain rotational knee laxity or if it will be just another vaporware.

Funding The authors have not declared a specific grant for this research from any funding agency in the public, commercial or not-for-profit sectors.

Competing interests None declared.

Patient consent for publication Not required.

Provenance and peer review Commissioned; externally peer reviewed.

\section{(2) \\ OPEN ACCESS}

Open access This is an open access article distributed in accordance with the Creative Commons Attribution Non Commercial (CC BY-NC 4.0) license, which permits others to distribute, remix, adapt, build upon this work non-commercially, and license their derivative works on different terms, provided the original work is properly cited, an indication of whether changes were made, and the use is non-commercial. See: http:// creativecommons.org/licenses/by-nc/4.0/.

(C) International Society of Arthroscopy, Knee Surgery and Orthopaedic Sports Medicine 2021. Re-use permitted under CC BY-NC. No commercial re-use. Published by BMJ.

\section{Check for updates}

To cite Espregueira-Mendes J. J ISAKOS

2021:6:63-65.

\section{SLinked}

- http://dx.doi.org/10.1136/jisakos-2019-000339

http://dx.doi.org/10.1136/jisakos-2019-000360

http://dx.doi.org/10.1136/jisakos-2019-000368

J ISAKOS 2021:6:63-65.

doi:10.1136/jisakos-2020-000529

\section{ORCID iD}

João Espregueira-Mendes http://orcid.org/0000-00017429-4900

\section{REFERENCES}

1 Claes S, Vereecke E, Maes M, et al. Anatomy of the anterolateral ligament of the knee. J Anat 2013;223:321-8

2 Iseki T, Rothrauff BB, Kihara S. Paediatric knee anterolateral capsule does not contain a distinct ligament: analysis of histology, immunohistochemistry and gene expression. J Isakos 2021;6:82-7.

3 Neri T, Dabirrahmani D, Beach A. Different anterolateral procedures have variable impact on knee kinematics and stability when performed in combination with anterior cruciate ligament reconstruction. J Isakos 2021;6:74-81.

4 Neri T, Cadman J, Beach A. Lateral tenodesis procedures increase lateral compartment pressures more than anterolateral ligament reconstruction, when performed in combination with $\mathrm{ACL}$ reconstruction: a pilot biomechanical study. J Isakos 2021;6:66-73.

5 Segond P. Recherches cliniques et expérimentales sur les épanchements sanguins du genou par entorse. Paris: Bureaux du Progrès médical, 1879.

6 Murgier J, Devitt BM, Sevre J, et al. The origin of the knee anterolateral ligament discovery: a translation of Segond's original work with commentary. Arthroscopy 2019;35:684-90

7 Cavaignac E, Ancelin D, Chiron P, et al. Historical perspective on the "discovery" of the anterolateral ligament of the knee. Knee Surg Sports Traumatol Arthrosc 2017;25:991-6.

8 Campos JC, Chung CB, Lektrakul N, et al. Pathogenesis of the Segond fracture: anatomic and MR imaging evidence of an iliotibial tract or anterior oblique band avulsion. Radiology 2001;219:381-6.

9 Vieira ELC, Vieira EA, da Silva RT, et al. An anatomic study of the iliotibial tract. Arthroscopy 2007;23:269-74

10 Vincent J-P, Magnussen RA, Gezmez F, et al. The anterolateral ligament of the human knee: an anatomic and histologic study. Knee Surg Sports Traumatol Arthrosc 2012:20:147-52.

11 Caterine S, Litchfield R, Johnson M, et al. A cadaveric study of the anterolateral ligament: re-introducing the lateral capsular ligament. Knee Surg Sports Traumatol Arthrosc 2015:23:3186-95.

12 Dodds AL, Halewood C, Gupte CM, et al. The anterolateral ligament: anatomy, length changes and association with the Segond fracture. Bone Joint J 2014;96-B;::.325-31. -b(3).

13 Helito CP, do Prado Torres JA, Bonadio MB, et al. Anterolateral ligament of the fetal knee: an anatomic and histological study. Am J Sports Med 2017;45:91-6.

14 Kennedy MI, Claes S, Fuso FAF, et al. The anterolateral ligament: an anatomic, radiographic, 
and biomechanical analysis. Am J Sports Med 2015:43:1606-15.

15 Herbst E, Albers M, Burnham JM, et al. The anterolateral complex of the knee: a pictorial essay. Knee Surg Sports Traumatol Arthrosc 2017:25:1009-14.

16 Musahl V, Rahnemai-Azar AA, van Eck CF, et al. Anterolateral ligament of the knee, fact or fiction? Knee Surg Sports Traumatol Arthrosc 2016;24:2-3.

17 Herbst E, Albers M, Burnham JM, et al. The anterolateral complex of the knee. Orthop I Sports Med 2017:5:2325967111773080.

18 Musahl V, Herbst E, Burnham JM, et al. The anterolateral complex and anterolateral ligament of the knee. J Am Acad Orthop Surg 2018:26:261-7.

19 Dombrowski ME, Costello JM, Ohashi B, et al. Macroscopic anatomical, histological and magnetic resonance imaging correlation of the lateral capsule of the knee. Knee Surg Sports Traumatol Arthrosc 2016;24:2854-60.

20 Andrade R, Rebelo-Marques A, Bastos R, et al. Identification of normal and injured anterolateral ligaments of the knee: a systematic review of magnetic resonance imaging studies. Arthroscopy 2019;35:1594-613.

21 Ariel de Lima D, Helito CP, Lacerda de Lima L, et al. Study of the nerve endings and mechanoreceptors of the anterolateral ligament of the knee. Arthroscopy 2019;35:2918-27.

22 Ariel de Lima D, Helito CP, Lacerda de Lima L, et al. Anatomy of the anterolateral ligament of the knee: a systematic review. Arthroscopy 2019;35:670-81.

23 Getgood A, Brown C, Lording T, et al. The anterolateral complex of the knee: results from the International alc consensus group meeting. Knee Surg Sports Traumatol Arthrosc 2019;27:166-76.

24 Zens M, Feucht MJ, Ruhhammer J, et al. Mechanical tensile properties of the anterolateral ligament. J Exp Orthop 2015:2:7.

25 Helito CP, Bonadio MB, Rozas JS, et al. Biomechanical study of strength and stiffness of the knee anterolateral ligament. BMC Musculoskelet Disord 2016:17:193.

26 Rahnemai-Azar AA, Miller RM, Guenther D, et al. Structural properties of the anterolateral capsule and lliotibial band of the knee. Am J Sports Med 2016;44:892-7.

27 Noyes FR, Butler DL, Grood ES, et al. Biomechanica analysis of human ligament grafts used in kneeligament repairs and reconstructions. J Bone Joint Surg Am 1984;66:344-52

28 Marom N, Ouanezar $\mathrm{H}$, Jahandar $\mathrm{H}$, et al. Lateral extraarticular Tenodesis reduces anterior cruciate ligament graft force and anterior tibial translation in response to applied pivoting and anterior Drawer loads. Am J Sports Med 2020;48:3183-93.

29 Engebretsen L, Lew WD, Lewis JL, et al. The effect of an iliotibial tenodesis on intraarticular graft forces and knee joint motion. Am J Sports Med 1990;18:169-76.

30 Noyes FR, Huser LE, Jurgensmeier $D$, et al. Is an anterolateral ligament reconstruction required in ACL-Reconstructed knees with associated injury to the anterolateral structures? A robotic analysis of rotational knee stability. Am I Sports Med 2017;45:1018-27

31 Novaretti JV, Arner JW, Chan CK, et al. Does lateral extra-articular Tenodesis of the knee affect anterior cruciate ligament graft in situ forces and Tibiofemoral contact pressures? Arthroscopy 2020;36:1365-73.
32 Devitt BM, Bouguennec N, Barfod KW, et al. Combined anterior cruciate ligament reconstruction and lateral extra-articular tenodesis does not result in an increased rate of osteoarthritis: a systematic review and best evidence synthesis. Knee Surg Sports Traumatol Arthrosc 2017:25:1149-60.

33 Inderhaug E, Stephen JM, Williams A, et al. Biomechanical comparison of anterolateral procedures combined with anterior cruciate ligament reconstruction. Am J Sports Med 2017;45:347-54.

34 Trentacosta N, Pace JL, Metzger M, et al. Biomechanical evaluation of pediatric anterior cruciate ligament $(\mathrm{ACL})$ reconstruction techniques with and without the anterolateral ligament (all). J Pediatr Orthop 2020:40:8-16.

35 Jette C, Gutierrez D, Sastre S, et al. Biomechanical comparison of anterolateral ligament anatomical reconstruction with a semi-anatomical lateral extra-articular tenodesis. A cadaveric study. Knee 2019;26:1003-9.

36 Delaloye J-R, Hartog C, Blatter S, et al. Anterolateral ligament reconstruction and modified Lemaire lateral extra-articular Tenodesis similarly improve knee stability after anterior cruciate ligament reconstruction: a biomechanical study. Arthroscopy 2020:36:1942-50.

37 Smith PA, Thomas DM, Pomajzl RJ, et al. A biomechanical study of the role of the anterolateral ligament and the deep Iliotibial band for control of a simulated pivot shift with comparison of minimally invasive extra-articular anterolateral tendon graft reconstruction versus modified Lemaire reconstruction after anterior cruciate ligament reconstruction. Arthroscopy 2019;35:1473-83.

38 Katakura M, Koga H, Nakamura T, et al. Biomechanical effects of additional anterolateral structure reconstruction with different femoral attachment sites on anterior cruciate ligament reconstruction. Am J Sports Med 2019:47:3373-80.

39 Drews BH, Kessler O, Franz W, et al. Function and strain of the anterolateral ligament Part II: reconstruction. Knee Surg Sports Traumatol Arthrosc 2020. doi:10.1007/s00167-020-06137-8. [Epub ahead of print: $25 \mathrm{Jul} 2020]$.

40 Getgood AMJ, Bryant DM, Litchfield R, et al. Lateral extra-articular Tenodesis reduces failure of hamstring tendon autograft anterior cruciate ligament reconstruction: 2-year outcomes from the stability study randomized clinical trial. Am J Sports Med 2020:48:285-97.

41 Helito CP, Sobrado MF, Giglio PN, et al. Combined Reconstruction of the Anterolateral Ligament in Patients With Anterior Cruciate Ligament Injury and Ligamentous Hyperlaxity Leads to Better Clinical Stability and a Lower Failure Rate Than Isolated Anterior Cruciate Ligament Reconstruction. Arthroscopy 2019:35:2648-54.

42 Hurley ET, Fried JW, Kingery MT, et al. Antero-lateral ligament reconstruction improves knee stability alongside anterior cruciate ligament reconstruction. Knee Surg Sports Traumatol Arthrosc 2020. doi:10.1007/s00167-020-06002-8. [Epub ahead of print: 22 Apr 2020] (Published Online First: 22 April 2020).

43 Hamido F, Habiba AA, Marwan Y, et al. Anterolateral ligament reconstruction improves the clinical and functional outcomes of anterior cruciate ligament reconstruction in athletes. Knee Surg Sports Traumatol Arthrosc 2020.
44 Helito CP, Camargo DB, Sobrado MF, et al. Combined reconstruction of the anterolateral ligament in chronic ACL injuries leads to better clinical outcomes than isolated ACL reconstruction. Knee Surg Sports Traumatol Arthrosc 2018;26:3652-9.

45 Rowan FE, Huq SS, Haddad FS. Lateral extra-articular tenodesis with $\mathrm{ACL}$ reconstruction demonstrates better patient-reported outcomes compared to $\mathrm{ACL}$ reconstruction alone at 2 years minimum follow-up. Arch Orthop Trauma Surg 2019;139:1425-33.

46 Alm L, Drenck TC, Frosch K-H, et al. Lateral extra-articular tenodesis in patients with revision anterior cruciate ligament $(\mathrm{ACL})$ reconstruction and high-grade anterior knee instability. Knee 2020;27:1451-7.

47 Yoon KH, Hwang IU, Kim EJ, et al. Anterolateral ligament reconstruction improves anteroposterior stability as well as rotational stability in revision anterior cruciate ligament reconstruction with high-grade pivot shift. J Knee Surg 2020. doi:10.1055/s-0040-1708055. [Epub ahead of print: 05 May 2020] (Published Online First: 5 May 2020).

48 Ibrahim SA, Shohdy EM, Marwan Y, et al. Anatomic reconstruction of the anterior cruciate ligament of the knee with or without reconstruction of the anterolateral ligament: a randomized clinical trial. $A m J$ Sports Med 2017:45:1558-66.

49 Ahn JH, Lee SK, Mun JW, et al. Degree of anterolateral ligament injury impacts outcomes after Double-Bundle anterior cruciate ligament reconstruction. Arthroscopy 2021;37:222-30.

50 Hohmann E. Editorial commentary: another take on the anterolateral ligament: high-grade are worse than low-grade injuries, but the categorization is problematic. Arthroscopy 2021;37:231-3.

51 Grassi A, Zicaro JP, Costa-Paz M, et al. Good mid-term outcomes and low rates of residual rotatory laxity, complications and failures after revision anterior cruciate ligament reconstruction $(\mathrm{ACL})$ and lateral extra-articular tenodesis (let). Knee Surg Sports Traumatol Arthrosc 2020;28:418-31.

52 Lee DW, Kim JG, Cho SI, et al. Clinical outcomes of isolated revision anterior cruciate ligament reconstruction or in combination with anatomic anterolateral ligament reconstruction. Am I Sports Med 2019:47:324-33.

53 Ventura A, Legnani C, Boisio F, et al. The association of extra-articular tenodesis restores rotational stability more effectively compared to contralateral hamstring tendon autografts $\mathrm{ACL}$ reconstruction alone in patients undergoing $\mathrm{ACL}$ revision surgery. Orthop Traumatol Surg Res 2020. doi:10.1016/j.0tsr.2020.06.022. [Epub ahead of print: 31 Dec 2020] (Published Online First: 31 December 2020).

54 Lagae KC, Robberecht J, Athwal KK, et al. Acl reconstruction combined with lateral monoloop tenodesis can restore intact knee laxity. Knee Surg Sports Traumatol Arthrosc 2020;28:1159-68.

55 Kittl C, El-Daou H, Athwal KK, et al. The role of the anterolateral structures and the ACL in controlling laxity of the intact and ACL-Deficient knee. Am J Sports Med 2016;44:345-54.

56 Araki D, Matsushita T, Hoshino Y, et al. The anterolateral structure of the knee does not affect anterior and dynamic rotatory stability in anterior cruciate ligament injury: quantitative evaluation with the electromagnetic measurement system. Am I Sports Med 2019;47:3381-8. 